\title{
Special Vocabulary and its Role in the Forming of the Communicative Competence of the Students from Multicultural Group in Special Secondary Educational Institutions
}

\author{
Marina Borovikova \\ State Musical College of Variety and Jazz Art \\ Moscow, Russia
}

\begin{abstract}
In the article it is said about the importance of learning terminology by the bilingual students at the lessons of Russian as a foreign language. The article not only gives a historical reference to the appearance of the terminology, but also puts a question of learning special terminology. It also gives the methods of solving this problem, as there is no understanding between the specialists of one profession without the knowledge of terminology. The bilingual students' ability to combine terms on the basis of their knowledge makes their speech more professional and exact [1].
\end{abstract}

Keywords-terminology; bilingual students; Russian as a foreign language

\section{INTRODUCTION}

In connection with the development of the new technologies and opening of new tendencies in all the spheres of science (natural sciences, exact sciences and liberal arts), the vocabulary of the Russian language is actively replenished with the terms, and in connection with it the science terminology is also developing. With the process of globalization there began an intensified integration tendency in science, culture and education, which gave an opportunity to get (draw,borrow) new words from the common receptacle (more often of European languages) and to use this vocabulary as terms. Integration tendencies induced a powerful current of a new special vocabulary, which became necessary and penetrating in all the spheres of human activities. Among the scientists the problem of the vocabulary integration induces strong discussions, and there also appears the discontent of the scientists, who fight for the purity of the Russian language. The integration is inevitable and rightful in the majority of cases, because in the science, culture and education the integration tendencies are also intensifying [2]. The word stock of the language in expanding as well as the stock of special vocabulary.

\section{FROM THE HISTORY OF TERMINOLOGY}

Of course, the terms appeared earlier than the science about them. The terms exist from the ancient times. Everything new that appeared in any sphere in a course of time acquired its name, i.e. term. The scientists paid a serious attention to this aspect of the vocabulary in the 19th century. Though the time of appearance of the first terms is disputable. Every epoch brought its terms. The terms were based on the close lexical meaning of the native language, but sometimes the term was created with the help of a foreign language (Latin, German, English etc.) There also existed the terms which appeared almost simultaneously in different languages, because the conception which is denoted as a term, was getting more urgent in peoples' life. For example, etymologically the terms "ethics", "morality" and "morals" appeared in different languages in different time, but denote the same notion "custom", "morals and manners". Many terms have their specific author. For example, the word "influence" was translated from French by N.M. Karamzin, who used morphemic tracing. A lot of terms with the lapse of time fell apart as terms, acquiring some additional meanings [3]. With the expansion of the information field of some terms there appear homonyms. In order to get to the bottom of this aspect of the language at the turn of the 19-20 centuries a new linguistic science - terminology appeared, as well as the linguists-terminologists.

If earlier the term was considered only as a neologism, which had only one meaning in a specific field of science, today the definition of a term is becoming more complex.

In numerous encyclopedic, linguistic dictionaries and dictionaries of foreign words the definition given to the term is approximately identical, but is more often capacious and verbose, for example:

The term (from lat. terminus - a limit, border) - a word or a word combination which is the name of some concept of any field of science, technology, art, etc.(Wikipedia)

Term (lat. terminus). 1) the accepted conditional expression, the name peculiar to any science, trade. 2) a period of time(term). 3) of Romans: the God of borders to whom festival of terminalia was established. 4) boundary post, column. 5) in logic: the concept name, as a part of judgment. ("The dictionary of the foreign words which have entered into the composition of the Russian language".Chudinov A.N. 1910) 
Term:1) accepted by all in the fields of science, art or trade the name of a subject or an action, or the whole expression shortly and clearly transferring the known idea; legal, philosophical, medical, military, sea, musical and many others terms are distinguished; 2) a period of time. ("The unabridged dictionary of the foreign words which have entered the use in the Russian language". Popov M., 1907)

It is possible to speak about an origin of this or that term, but it is important that terms were gradually arising during all the periods of life and epochs. Especially intensive formation of new terms in Russia began at the end of the 18th -beginning of the 19th century. As a science, terminology was developed much later, even later than compiling of the dictionaries which included terms of certain fields of science, culture, education. Terms carry out a certain communicative function in the experts' environment.

\section{GOALS AND OBJECTIVES}

We know that language embodies the unity of processes of communication, cognition, formation of the personality. In these conditions the goals and objectives of learning the language draw closer to the purposes and problems of preoccupational and occupational training of pupils - bilinguals. Pupils-bilinguals - this term is the most successful, so far as it concerns students from the former federal republics of the USSR who are studying at the specialized secondary schools in Russia at present.

The pupils of Special Secondary Educational Institutions, mastering the future profession, must not only know Russian well, but also be able to solve a number of specific tasks. And firstly all the students need to acquire special terminology because the communicative function of terminological vocabulary consists in ensuring mutual understanding between specialists within appropriate sections of knowledge and, of course, within the professional activity. Accuracy, flexibility, expressiveness of the speech of future experts depends on high-quality possession of professional terminology - depths of penetration into system of values of professional terms, the ability to combine terms on the basis of knowledge of their system connections.

If a student gets mixed up with the terminology it can lead to a communicative failure - the misunderstanding of the communicative partner's utterance. It is highly vital for the graduates because after getting a diploma they become competent specialists [4].

The contradiction between the level of communicative, professional-terminological competency of the students to the perception of the educational information, the requirements of secondary specialized educational institutions and their future professional activity becomes a problem for the successful entrance of bilingual students into the academic process and professional activity. In connection with that appears a constant necessity for the enrichment of the vocabulary of bilingual students with new terms.

After analyzing the problem, it can be said that the replenishment of the student's vocabulary with professional terminology is singled out into a special sphere of speech development in modern methodology of the Russian language, where there is its own subject, research methods, contents and educational methods. The methodology of teaching terminology is closely connected to teaching the proper way of reading specialized literature. L. M. Andrenko, A. B. Kazakov, G. P. Klepikova, I. S. Kucherova, N. L. Serdukova, L. P. Tsybina, etc. wrote about it.

The methodology of terminology teaching has to be examined in the process of teaching all the aspects of language: pronunciation, vocabulary, grammar and also all the types of speech activities (speaking, reading, listening and writing).

Along with that the enrichment of students' vocabulary implies the following goals:

to enrich the personal vocabulary of bilingual students with new terms, that is to achieve a qualitative increase of word stock of every bilingual student.

to enlarge the vocabulary which helps to ascertain and specify the lexical meaning of new terms, to learn their specific compatibility and peculiarities of their usage.

to help find the place of the term in the word-building family, in the synonymic chain, in the antonymous pair independently. The term has to induce a number of associations with other terms in the mind of bilingual students. This is in the particular basis for the right usage of the words. The task of the teacher, who is working in multi-cultural groups, is to activate the systemic associative connection of the terms and, based on that, create an active vocabulary and make it more flexible, variable and functional.

to include bilingual students into speech activity, using the factors of motivational influence.

to develop the mastery of orthographic norms of the right spelling of the term, of the free usage of the terms according to the particular speech situation.

to develop the necessity of vocabulary enlargement for bilingual students, the necessity for attention to professional terms and to activate the desire of bilingual students to replenish their vocabulary by themselves.

\section{Method of teaching terms}

It should also be noted that the mastery of professional terminological vocabulary is not limited to:

\section{finding words in a specialized dictionary}

simple memorizing the necessary terms list.

The implementation of this complex and integrated task is connected with many difficulties of linguistic and extra linguistic nature. It demands a serious linguistic training from a future professional.

As the theoretical and practical analysis of this research issue shows, the selection and building of the educational material on the basis of subject-orientation and professional value and also the communicative and speech situation in particular develops all the components of communicative and professional and terminological competency of bilingual students. Scholars say that during the language material 
selection it is necessary to take into consideration the linguistic way of foreigners' world perception. For example, the Italian word "statista" (a politician) coincides in spelling and pronunciation with the Russian borrowing from the German language "статист" (an extra, der Statist), which remains in the Russian language, but has a whole different lexical meaning. Another example is the English word "compositor". It is not something we are used to hear [6]. A print shop worker is not a creator of music. Therefore the phrase from the well-known short story about Sherlock Holmes sounds strange, because in the Russian translation, when the great detective saw someone with the hands stained with printing paint, he immediately realized that this person was a composer (композитор, compositor in Russian).

Other Russian linguists bring more interesting examples: "spring" has become a term for wheat and spring onions, because these plants are sown in spring. There is a distinction in the Russian language between spring onions (a colour distinction) and root onions (a shape distinction) and wheat can be called spring crops (yarovaya) by the name of an ancient goddess of fertility. And there are lots of examples like that.

The fact that Russian and foreign words coincide in their meaning does not imply that they mean the same thing. Therefore one should be very careful while translating from one language into another. Translating the phrases literally, we can get an absolutely misrepresented way of world-perception. The language is always closely connected to the nation's way of life. It comes to the fact that vocabulary in Moscow and Saint Petersburg diverges sometimes (white bread is called "bun" (bulka) in St. Petersburg and "long loaf" (baton) in Moscow and in Bulgarian this word can be translated in Russian as "bride"). If we go back to Italian, we can see that the "mark" is not "given" but "laid". The Germans congratulate not "with" a holiday, but "to" one (zum Geburtstag). This is more serious with the translation of idiomatic expressions (idioms). The witty jokes of a great linguist L. Uspensky can serve as an example here. The phrase "Hello, I am your aunt!" was translated as "She is saying that she is your relative".

The words, which do not coincide in their main lexical meaning and also the words, which main lexical meaning coincides, can be used to create new terms.

The methodology of teaching students the Russian language as a foreign or second language should be examined in connection with teaching the ways of reading specialized literature (literature, connected with the future profession).

Vocabulary work, which develops the attention to the professional terminological vocabulary and to proper writing and usage of the terms is very important for the enlargement of the vocabulary with new terms. This methodology is dedicated to the training of the ability and desire of bilingual students to improve their knowledge, extend their vocabulary and apply to special dictionaries and reference books.

After analyzing and studying all the peculiarities of communicative competence and the peculiarities of competence contents there can be singled out a basic set of exercises: language

relative-vocal(speech)

communicative

Therefore we can say that the realization of speech (professional) communication implies the presence of comprehensive and usage skills for specific language. The most important part of it is terminology.

It is necessary to mention that the mastery of special terminology in the second foreign language is a complicated and versatile process, which cannot be fully examined in this article. The mastery of terminology meets the necessity of communication in the second foreign language and assists in forming and improvement of foreign professional-directed, communicative and professional-terminological vocabulary.

\section{CONCLUSION}

Now the further prospects in the research in this field can be contemplated. It is the scientific substantiation and the experimental check of conditions, which can provide the service part of the process, that is the mastery of professional terminology of bilingual students. It is necessary to develop a model of forming the communicative competency of bilingual students, which provides a purposeful control over the process of development of the student's personality and implements the main points of this process due to examination of the level of the analyzed competency, the usage of the material contents to form the professionally important qualities of the future specialists.

\section{REFERENCES}

[1] Averbukh K. Ya. Standardization of terminology: selected results and prospects (to ... Second International School - cognitive linguistics seminar, 11 - 14 September 2000 / Pub. Ed. N.N. Boldyrev ... The Russian language: history, dialects, modernity: Collection of scientific papers.)

[2] Apresyan Yu. D. Ideas and the methods of contemporary structural linguistics. M., 1966.

[3] Akhmanova O. S. On the stylistic differentiation of words // Collection of articles on linguistics to the MSU Academician Vinogradov. M.: MSU, 1958.

[4] Akhmanova O. S. Scientific definition as a linguistic and semiotic issue // Problems of definitions in dictionaries of different types. M., 1976.

[5] Baranov A. N., Kobozeva I.M. Semantic meta-languages for the description of the meaning of a sentence // Linguistic support of information systems. M.: INION, 1989.

[6] P.Benveniste E. General Linguistics. Trans. from French / Ed. Yu. S. Stepanov. 2nd Stereotype Edition, M.: URSS, 2002.

[7] Buyanova L. Yu. Derivation of substantive terms and its reflection in study the dictionary (natural study subtype) // Contemporary issues of lexicography. Kharkov, 1992.

[8] Buyanova L. Yu. On the issues of term-formative specificity of the language of science (based on the natural study subtype) // Functionalsemantic aspects of the Russian word studies: Thes. interuniv. conf. P. I Orekhovo-Zuyevo, 1994.

[9] Buyanova L. Yu. On the issues of semantic structure of the derived term // Semantics of linguistic units. P. II Phraseological semantics. Wordformative semantics. M., 1994. 
[10] Buyanova L. Yu. Terminological Derivation of the Language of Science: Formation of the System // Science of Terminology / Ed. V. A. Tatarinov. M. 1995. No. 2-3.

[11] Buyanova L. Yu. Term as a Unit of Logos. Krasnodar, 2003.

[12] Vasilieva N. V. To the semantic and functional description of GrecoLatin term elements in the linguistic terminology // VYa. №3.

[13] Vassoevich N. B., Berger M. G. Methodical guidelines on formation and development of scientific and technical terminology and onomatology. M.: MSU, 1974.

[14] Vinogradov V. V. Introduction// Issues of terminology. M., 1961.

[15] Vinogradov V. V. Lexicology and Lexicography: Selected works / V. V. Vinogradov: (Pub.Ed. and Introduction by V. G. Kostomarov; ASUSSR, Ling. and Liter. Dept). M.: Science, 1977.

[16] Vinokur G. O. On Some Phenomena of Word Formation in Domestic Technical Terminology (1939) // V. A. Tatarinov. History of Russian Terminology. Classics of Terminology: Digest and Anthology. M., 1994.

[17] Volkova I. N. Standardisation of Scientific and Technical Terminology. M., 1984.

[18] Volodina M. N. Cognitive and Information Nature of Terms (based on the terminology of the mass media). M., 2000

[19] Gvishiani N. B. The language of scientific communication: The questions of Methodology M., 1994.

[20] Golovin B. N. About some aspects of studying of terms // MSU Journal. Philology. 1972. №5.

[21] Golovin B. N. Linguistic Terms and Linguistic Ideas // PL. 1976. №3.

[22] Golovin B. N., Kobrin R. Yu. Linguistic basis of the doctrine of terms учения. М., 1987.

[23] Grinev S. V. Terminological borrowings: Brief overview of the actual state of the matter // Lotte D. S. Problems of Borrowing and Ordering Foreign Terms and Term Elements. M.,1982.

[24] Grinev-Grinevich S. V. Introduction to terminography: How simple and easy to compile a dictionary Textbook. - 3rd revised ed. - M.: Publishing house «LIBROCOM», 2009.

[25] Danilenko V. P. Language for specific fields // Culture of the Russian speech and efficiency of communication. M., 1996.

[26] Gerebilo T. V. Linguistic Terms Dictionary. Nazran: Piligrim, 5th revised and corrected ed., 2010. http://Eerebilo.ucoz.ru/load/leksikogoafícheskie izdanija/slovar/slovar Hngvisticheskikh terminov 4 e izd/6-1-0-70

[27] Gerebilo T. V. Linguistic and stylistic abstraction as a study method. Magas: IngSU, 2003; Nalchik: El-Fa',

[28] 2005.http://gerebilo.ucoz.ru/load/monografii/monografiiayiingvostilistic heskaiaabstrakcijakak metod issledovanija/9-1-0-71

[29] Kandelaki T. L. Semantics and Motivation of Terms. M., 1977.

[30] Karasik V. I. Speech and social status. M.: ITDGK Gnozis, 2002.

[31] Kobozeva I. M. Linguistic semantics. M: URSS, 2004. 